\title{
Effect of Phototherapy on Serum Level of Calcium and Magnesium in Term and Preterm Neonates with Hyperbilirubinemia \\ Mohamed Mamdouh Gaafar ${ }^{1}$, Ehab Mahmoud Rasheed, Samar Mahmoud Abdel Halim ${ }^{2}$, Mousbah Mohamed Abdullah Mohamed El Gendi ${ }^{1}$ \\ Departments of ${ }^{1}$ Pediatrics, ${ }^{2}$ Clinical Pathology, Faculty of Medicine, Zagazig University, Egypt \\ *Corresponding author: Mousbah Mohamed Abdullah Mohamed El Gendi, Mobile: (+20) 1018213213, E-Mail: mousbahelgendi77@gmail.com
}

\begin{abstract}
Background: Hyperbilirubinemia is one of the most prevalent problems in neonates. Jaundice is observed during first week of life in approximately $60 \%$ of term neonates and $80 \%$ of preterm neonates. Phototherapy is one of the routine methods for management of hyperbilirubinemia. Many studies reported that serum levels of calcium and magnesium are significantly affected after 48 hours of exposure to phototherapy.

Objectives: The aim of the work was to study the effects of phototherapy on serum calcium and serum magnesium in full term and preterm neonates with hyperbiliurbinemia.

Patients and Methods: The current study was prospective cohort that was conducted in neonatal intensive care unit (NICU), Zagazig University children hospital in period between August 2018 to July 2019. 60 jaundiced infants admitted to (NICU) in the study. They were divided into 2 groups; Group I: 43 patients (full terms), Group II: 17 patients (preterms). Patients were examined for the effect of phototherapy on serum level of calcium and magnesium. Results: There was a statistically significant difference between serum calcium and serum magnesium before and after 48 hours of exposure to phototherapy $(\mathrm{P}<0.001)$. Calcium was distributed pre and post phototherapy as $9.63 \pm 0.79$ and $9.04 \pm 0.78$ respectively and Magnesium was distributed pre and post phototherapy as $2.17 \pm 0.23$ and $1.91 \pm 0.18$. Total bilirubin was distributed pre and post phototherapy as $16.76 \pm 2.99$ and $11.0 \pm 2.45$ respectively and direct bilirubin pre and post as $1.05 \pm 0.33$ and $1.05 \pm 0.32$ respectively. Preterm were $28.3 \%$ (17 in number) and fullterm were $71.7 \%$ (43 in number).
\end{abstract}

Conclusion: Based on the findings of our study, phototherapy can significantly decrease the levels of calcium and magnesium in jaundiced term and preterm infants undergoing phototherapy.

Keywords: Hyperbilirubinemia, Neonates, Phototherapy, Calcium, Magnesium.

\section{INTRODUCTION}

Neonatal jaundice or hyperbilirubinemia is an unpreventable condition in $60 \%-80 \%$ of newborns worldwide. In a proportion of infants, jaundice may become severe progressing to acute bilirubin encephalopathy or kernicterus with a significant risk of neonatal mortality. Surviving infants may acquire long-term neurodevelopmental sequelae such as cerebral palsy, sensorineural hearing loss, intellectual difficulties or gross developmental delay ${ }^{(\mathbf{1})}$.

Phototherapy plays a significant role in the treatment and prevention of hyperbilirubinemia in neonates. This relatively common therapy lowers the serum bilirubin level by transforming bilirubin into water-soluble isomers that can be eliminated without conjugation in the liver ${ }^{(2)}$.

The effectiveness of phototherapy depends upon the type of light source used (i.e. dose, spectral emission curve, depth of penetration), the distance between the light and the infant, the surface area treated, the etiology of the jaundice, and total serum bilirubin level at the onset of phototherapy ${ }^{(3)}$.

In the recent years, limited research showed that phototherapy should be considered as a risk factor for hypocalcemia and its mechanism is probably based on the effect of phototherapy on the decrease of melatonin leading to decrease in melatonin, spatter of reduced glucocorticoid, and increase in calcium resorption from bone that causes hypocalcemia ${ }^{(4)}$.

Magnesium is the fourth most abundant cation in the body and its vast majority is stored intracellularly. It is, however, the extracellular concentrations of the mineral that is of interest to the clinician due to its association with symptoms and signs. The major organs involved in magnesium homeostasis are the gut, bone, and kidney, but the regulators affecting these organs at the cellular level are not yet fully understood. Hypermagnesemia is rare and is seen mostly in those with renal failure and in the elderly. It is suggested that there is a positive correlation between plasma ionized $\mathrm{Mg}$ levels and severity of hyperbilirubinemia in newborn ${ }^{(5)}$.

Calcium, magnesium, are important elements in the body and phototherapy can lead to the decrease of serum calcium and magnesium in the blood. On the other hand, decrease in calcium and magnesium can cause certain complications such as apnea, muscular tick convulsion, and decrease in absorption of vitamin $\mathrm{D}$, which causes a decrease in the absorption of calcium. Therefore, any changes in the blood level cause 
irreparable effects, and might also influence the absorption of other elements ${ }^{(6)}$.

The aim of the current work was to study the effects of phototherapy on serum calcium and serum magnesium in full term and preterm neonates with hyperbilirubinemia.

\section{PATIENTS and MTHODS}

This prospective cohort study included a total of 60 jaundiced infants, attending at Neonatal Intensive Care Unit (NICU) Zagazig University Hospitals. This study was conducted between August 2018 to July 2019.

Ethical Clearance: Written Informed consent was taken from the patient parents to participate in the study. Approval for performing the study was obtained from Pediatrics and Clinical Pathology Departments, Zagazig University Hospitals after taking Institutional Review Board (IRB) approval. The work has been carried out in accordance with the code of ethics of the world medical association (Decleration of Helsinki) for studies involving humans.

The age of 60 infants ranged from 2 to 8 days. They were divided into two groups; Group (1) consisted of 43 full-term patients ( 31 males and 12 females) and Group (2) consisted of 17 preterm patients ( 7 males and 10 females).

Patients were examined for the effect of phototherapy on serum level of calcium and magnesium by evaluating serum magnesium and serum calcium levels alterations before and after phototherapy in hospitalized hyperbilirubinemic newborns undergoing phototherapy.

Inclusion criteria: Healthy, full-term, and preterm, appropriate for gestational age and exclusively breastfed newborns that were admitted for evaluation and treatment of non-hemolytic jaundice will be enrolled in the study.

Exclusion criteria: Newborns who had undergone exchange transfusion, had hemolysis, had been formula fed, had any congenital malformation, inborn errors of metabolism, proven sepsis or infection, or jaundice in the first 24 hours of life, or Phototherapy given for less than 48 hours or whose mothers had a history of diabetes will be excluded.

Table (1): Average Level of Total Bilirubin, Before and After Phototherapy

\begin{tabular}{|c|c|c|c|}
\hline Time of Test & $\begin{array}{l}\text { Total Bilirubin (Mean } \pm \text { SD) } \\
\text { mg/dL }\end{array}$ & $\begin{array}{l}\text { Maximum } \\
\text { Minimum }\end{array}$ & $\overline{P \text { P-value }}$ \\
\hline Hospitalization time & $16.76 \pm 2.99$ & $\begin{array}{l}21.1 \\
7.71\end{array}$ & \multirow{2}{*}{$<0.001$} \\
\hline $\begin{array}{l}48 \text { hours after } \\
\text { admission }\end{array}$ & $11.0 \pm 2.45$ & $\begin{array}{l}15.9 \\
5.2\end{array}$ & \\
\hline
\end{tabular}

All patients included in the study were subjected to the following:

Full history taking with particular emphasis on prenatal, natal and post-natal gestational age, sex (male/female), weight, family history of her sibling admitted to NICU with jaundice, history of the time of appearance of jaundice and its extension, complete physical examination with assessing intensity of jaundice and correlation to activity and anemia.

Clinical pathology investigations:

Measurement of total serum calcium (by spinreact calcium kit) serum magnesium levels (by spinreact magnesium kit), serum total and direct bilirubin (by spinreact bilirubin kits) before and 48 hours after end of exposure to phototherapy, blood grouping for mother and babies, hemoglobin concentration, reticulocytic count and Coomb's test were done.

To perform phototherapy, the subjects were placed at 15 to 20 centimeters from the light source (blue fluorescent (neon) lights) with a wave-length range of 420 to $470 \mathrm{~nm}$ above their heads

\section{Statistical Analysis}

Data collected throughout history, basic clinical examination, laboratory investigations and outcome measures coded, entered and analyzed using Microsoft Excel software. Data were then imported into Statistical Package for the Social Sciences (SPSS version 20.0) software for analysis. According to the type of data qualitative represent as number and percentage, quantitative continues group represent by mean $\pm \mathrm{SD}$, the following tests were used to test differences for significance; difference and association of qualitative variable by Chi square test (X2). Differences between quantitative independent groups by $\mathrm{t}$ test paired by paired t. P value was set at $<0.05$ for significant results $\&<0.001$ for high significant result.

\section{RESULTS}

Evaluation of the average level of serum bilirubin in subjects measured at two different times (at hospitalization and after 48 hours of exposure to phototherapy) showed a significant decrease in the level of bilirubin; level of bilirubin in those subjects after phototherapy had an average value of $16.76 \pm 2.99$ $\mathrm{mg} / \mathrm{dL}$, which was less than that of hospitalization time $11.0 \pm 2.45$ ( $\mathrm{P}<0.001)$. table (1) \& figure (1). 


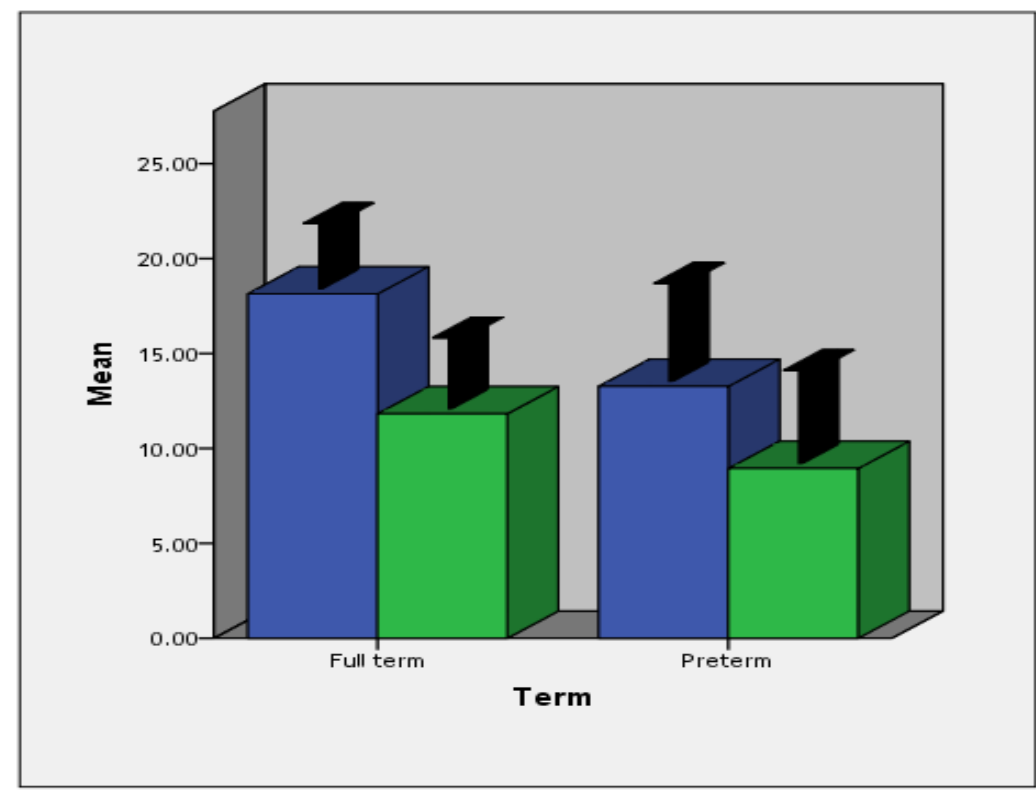

Error Bars: +/- $2 \mathrm{SD}$

Figure (1): Mean Total bilirubin pre and post phototherapy in term and preterm.

And Mean Total bilirubin pre and post phototherapy is higher in term infants than preterm infants.

Table (2): Average Level of Serum calcium, before and after Phototherapy

\begin{tabular}{||l|l|l|l||}
\hline Time of Test & $\begin{array}{l}\text { Serum Calcium } \\
\text { Level (Mean } \pm \\
\text { SD) } \mathbf{~ m g / d L}\end{array}$ & $\begin{array}{l}\text { Maximum } \\
\text { Minimum }\end{array}$ & P-value \\
\hline Hospitalization time & $9.63 \pm 0.79$ & $\begin{array}{l}11.76 \\
7.87\end{array}$ & \multirow{2}{*}{$<0.001$} \\
\hline $\begin{array}{l}\text { 48 hours after } \\
\text { admission }\end{array}$ & $9.04 \pm 0.78$ & $\begin{array}{l}10.35 \\
7.56\end{array}$ & \\
\hline
\end{tabular}

Statistical analysis showed that 48 hours after phototherapy, average serum calcium level in the subjects was $9.04 \pm 0.78 \mathrm{mg} / \mathrm{dL}$, which was less than that of the hospitalization time $(9.63 \pm 0.79$ $\mathrm{mg} / \mathrm{dL})$. This decrease was statistically significant $(\mathrm{P}<0.001)$. table $(\mathbf{2})$

Table (3): Average Level of Serum magnesium, before and after Phototherapy

\begin{tabular}{||l|l|l|l|}
\hline Time of Test & $\begin{array}{l}\text { Serum magnesium } \\
\text { Level (Mean } \pm \text { SD) } \\
\text { mg/dL }\end{array}$ & $\begin{array}{l}\text { Maximum } \\
\text { Minimum }\end{array}$ & P-value \\
\hline Hospitalization time & $2.17 \pm 0.23$ & 2.82 & \multirow{2}{*}{$<0.001$} \\
\cline { 1 - 3 } 48 hours after & $1.91 \pm 0.18$ & $\begin{array}{l}1.49 \\
1.64\end{array}$ & \\
\hline
\end{tabular}

Regarding the serum level of magnesium in the subjects, the average was $1.91 \pm 0.18 \mathrm{mg} / \mathrm{dL}$ after phototherapy, which was less than that of the hospitalization time $(2.17 \pm 0.23 \mathrm{mg} / \mathrm{dL})$ and the difference was statistically significant $(\mathrm{P}<0.001)$.table (3)

Table (4): Change assessment

\begin{tabular}{||l|l|l|l|l|}
\hline & Pre & Post & Paired t & P \\
\hline $\begin{array}{l}\text { Total Bilirubin } \\
\text { mg/dl }\end{array}$ & $16.76 \pm 2.9$ & $11.0 \pm 2.45$ & 19.664 & $0.00^{* *}$ \\
\hline Calcium mg/dl & $9.63 \pm 0.79$ & $9.04 \pm 0.78$ & 10.965 & $0.00^{* *}$ \\
\hline Mg mg/dl & $2.17 \pm 0.23$ & $1.91 \pm 0.18$ & 14.525 & $0.00^{* *}$ \\
\hline
\end{tabular}

Change assessment (Magnesium, Calcium, and bilirubin). are shown in table (4) 
Table (5): Term distribution, Gestational age (GA) in weeks, and Sex of baby distribution among studied group

\begin{tabular}{|c|c|c|c|}
\hline & & $\overline{\mathbf{N}}$ & $\%$ \\
\hline \multirow[t]{3}{*}{ Term } & Full term & 43 & 71.7 \\
\hline & Preterm & 17 & 28.3 \\
\hline & Total & 60 & 100.0 \\
\hline \multirow{3}{*}{ Sex of baby } & Female & 22 & 36.7 \\
\hline & Male & 38 & 63.3 \\
\hline & Total & 60 & 100.0 \\
\hline \multicolumn{4}{|l|}{ GA Weeks } \\
\hline \multicolumn{2}{|l|}{ Mean \pm SD } & \multicolumn{2}{|l|}{$37.01 \pm 2.41$} \\
\hline \multicolumn{2}{|l|}{ Median (Range) } & \multicolumn{2}{|l|}{$38.0(32-40)$} \\
\hline
\end{tabular}

GA was distributed according to our patients as $37.01 \pm 2.41$ with minimum 32 weeks and maximum 40 weeks. And in our study, Male were $63.3 \%$ (38 in number) and female $36.7 \%$ (22 in number). Preterm were $28.3 \%$ (17 in number) and full-term were $71.7 \%$ (43 in number). table (5)

Table (6) all parameters of the studied infants

\begin{tabular}{|l|l|l|l|l|}
\hline & $\begin{array}{l}\text { Full term } \\
(\mathbf{N}=\mathbf{4 3})\end{array}$ & $\begin{array}{l}\text { Preterm } \\
(\mathbf{N = 1 7 )}\end{array}$ & $\mathbf{T}$ & $\mathbf{P}$ \\
\hline Age at admission / day & $4.75 \pm 1.51$ & $3.64 \pm 1.22$ & 2.237 & $0.029^{*}$ \\
\hline Weight at admission/kg & $3.01 \pm 0.15$ & $2.1 \pm 0.46$ & 11.429 & $0.00^{* *}$ \\
\hline HB (g/dl) & $15.65 \pm 1.09$ & $15.47 \pm 0.88$ & 0.601 & 0.550 \\
\hline Reticulocyte count & $1.86 \pm 0.66$ & $2.05 \pm 0.48$ & $-1.115-$ & 0.269 \\
\hline Total Bilirubin pre (mg/dl) & $18.14 \pm 1.76$ & $13.27 \pm 2.6$ & 8.352 & $0.00^{* *}$ \\
\hline Total Bilirubin post(mg/dl) & $11.82 \pm 1.9$ & $8.94 \pm 2.4$ & 4.811 & $0.00^{* *}$ \\
\hline Calcium pre mg/dl & $9.57 \pm 0.84$ & $9.79 \pm 0.65$ & -0.970 & 0.336 \\
\hline Calcium post mg/dl & $8.97 \pm 0.81$ & $9.23 \pm 0.74$ & -1.120 & 0.267 \\
\hline Mg pre mg/dl & $2.14 \pm 0.21$ & $2.26 \pm 0.26$ & $-1.840-$ & 0.071 \\
\hline Mg post mg/dl & $1.9 \pm 0.18$ & $1.94 \pm 0.16$ & -0.906 & 0.369 \\
\hline
\end{tabular}

All parameters of the studied infants (Magnesium, Calcium, bilirubin, Age at admission, Weight at admission, HB and Reticulocyte count) are shown in table (6)

\section{DISCUSSION}

Hyperbilirubinemia or jaundice is a common problem and it is often considered benign in infants. Jaundice might be observed at the birth or any time during infancy. Therefore, if hyperbilirubinemia, which is non-conjugated, is not treated early, bilirubin crosses the blood-brain barrier and exerts its neurotoxic effects. Its therapy includes medicine therapy, blood exchange, and phototherapy ${ }^{(7)}$.

Phototherapy has a significant role in the treatment of hyperbilirubinemia in neonates ${ }^{(8)}$. However, this method may result in the development of some complications as hypocalcemia and hypomagnesemia (9). The current study was aimed at investigating the effects of phototherapy on serum level of calcium and magnesium in infants with jaundice at Zagazig University Hospital. Results of the current study showed that the level of calcium in term and preterm infants undergoing phototherapy with average of 9.04 $\mathrm{mg} / \mathrm{dL}$ was less than that of the hospitalization time with an average of $9.63 \mathrm{mg} / \mathrm{dL}$ and this decrease was statistically significant. And also level of magnesium in term and preterm infants undergoing phototherapy with average of $1.91 \mathrm{mg} / \mathrm{dL}$ was less than that of the hospitalization time with an average of $2.17 \mathrm{mg} / \mathrm{dL}$ and this decrease was statistically significant; similar to the results of the study by Barak et al. ${ }^{(10)}$ that showed calcium level of serum was reduced significantly, 24, 48, and 72 hours after phototherapy. Also, the outcomes of the current study were in accordance with those of the investigations by Sethi et al. ${ }^{(11)}$ that showed $90 \%$ of preterm infants and $75 \%$ of full-term infants during phototherapy developed hypocalcemia. In the study undertaken by Imani et al. ${ }^{(12)}$, serum bilirubin and magnesium levels were measured before and after phototherapy, both of which showed a significant decrease. Also, Khosravi et al. ${ }^{(13)}$, reported that phototherapy can decrease the total magnesium.

The results of these two studies as well as the results of the current study showed that average serum magnesium level decreased after phototherapy. In the study conducted by Sarici et al. ${ }^{(14)}$, there was a positive relationship between the levels of bilirubin and magnesium in ionized plasma. In the group with severe hyperbilirubinemia, magnesium level of ionized serum was significantly higher in comparison with that of the moderate group. Also, in this group, there was a positive and significant relationship between serum 
level of magnesium and intensity of hyperbilirubinemia. In the current study, the serum level of magnesium decreased through relieving hyperbilirubinemia and it maybe that the increase in the plasma level of magnesium was due to synchronization with hyperbilirubinemia; hence, after decrease in bilirubin, the level of magnesium decreased.

Romagnoli et al. ${ }^{(15)}$ was the first to suggest the association of hypocalcaemia in newborn following phototherapy. Hakinson et al. (16) and Hunter (17) hypothesized that phototherapy inhibits secretion of melatonin from pineal gland which blocks the effect of cortisol on bone calcium. So, cortisol increases bone uptake of serum calcium and induces hypocalcemia. Kim and Park ${ }^{(18)}$ suggested that decreased secretion of parathyroid hormone is the cause of hyopcalcemia in phototherapy.

Our result is in agreement with studies by Arora et al. (19) in which Hypocalcemia is a significant problem in neonates subjected to phototherapy which is a commonly used modality of treatment for neonatal hyperbilirubinemia hence there is need for closed monitoring of serum calcium levels and prophylactic c calcium supplementation in neonates subjected to phototherapy.

Conclusions: in this study it could be concluded that phototherapy can significantly decrease the levels of calcium and magnesium in jaundiced term and preterm infants undergoing phototherapy for 48 hours.

Recommendations: monitoring serum calcium and serum magnesium levels in newborns undergoing phototherapy for 48 hours or more and identify the reason and supplementation of calcium and magnesium to newborn after phototherapy especially preterm babies.

Limitations: In this study, we did not ethically allow to get a control group with the same bilirubin level who were not treated with phototherapy.

\section{Acknowledgement:}

The authors are grateful for the patients without whom this study wouldn't have been done.

\section{REFERENCES}

1. Olusanya BO, Osibanjo FB, Slusher TM (2015): Risk Factors for Severe Neonatal Hyperbilirubinemia in Low and Middle-Income Countries: A Systematic Review and MetaAnalysis. PLoS One, 10(2): e0117229.

2. Stokowski LA (2006): Fundamentals of phototherapy for neonatal jaundice. Adv Neonatal Care, 6:303-12.

3. Ebbesen F, Agati G, Pratesi $R$ (2003): Phototherapy with turquoise versus blue light. Arch Dis Child Fetal Neonatal Ed., 88:430-31.
4. Thomas B, Newman MD, Liljestrand $P$ et al. (2006): Outcomes among Newborns with Total Serum Bilirubin Levels of $25 \mathrm{mg}$ per Deciliter or More. N Engl J Med., 354: 1889-1900.

5. Chaim K, Uri SA (2013): Magnesium homeostasis and hypomagnesemia in children with malignancy. Pediatr Blood Cancer, 60:734-40.

6. Kliegman R, Stoll B (2011): Jaundice and hyperbilirubinemia in the newborn. In: Behemen R, Kliegman R, Jenson H, editors. Nelson Textbook of Pediatrics. 18th edn. Philadelphia: Saunders, Pp. 756-65.

7. Martin R, Fanaroff A, Walsh M (2015): Disorders of Calcium, Phosphorus, and Magnesium in the Neonate. Neonatal-Perinatal Medicine. Elsevier, Pp.1461-1489

8. Barrington KJ, Sankaran K (2014): Guidelines for detection, management and prevention of hyperbilirubinemia in term and late preterm newborn infants. Pediatrics, 114(4):917-24

9. Basiglio CL, Arriaga SM, Pelusa F (2010): Complement activation and disease: protective effects of hyperbilirubinemia. Clin Sci (Lond), 118:99-113.

10. Barak M, Mirzarahimi M, Eghbali M et al. (2014): The Effect of Phototherapy Duration on Serum Level of Total Calcium and 25-hydroxy vita- min D $(25(\mathrm{OH}) \mathrm{D})$ in Jaundiced Neonates. Int $\mathbf{J}$ Health Rehabil Sci., 123(127):3-4.

11. Sethi H, Saili A, Dutta AK (2011): Phototherapy induced hypocalcemia. Indian Pediatrics, 30: 140306.

12. Imani M, Rezaee-pour $M$, Mohamdi $M$ et al. (2012): Study of relationship between total Magnesium and total bilirubin levels in neonates' sera before and after phototherapy. RJMS., 19 (100): 54-61.

13. Khosravi N, Aminian A, Taghipour R (2011): Total serum magnesium level in icteric neonates before and after phototherapy. Tehran Univ Med J., 69 (7): 432-37.

14. Sarici SU, Serdar MA, Erdem G et al. (2004): Evaluation of plasma ionized magnesium levels in neonatal hyperbilirubinemia. Pediatr Res., 55(2):2437.

15. Romagnoli C, Polidore G, Cataldi L et al. (1979): Phototherapy induced hypocalcaemia. J Pediatr., 94(5):815-16.

16. Hakinson D, Penny R, Bergstrom W (1987): Calcemic responses to photic and pharmacologic manipulation of serum melatonin. Pediatr Res., 22(4):414-6.

17. Hunter K (2004): Hypocalcemia. In: Cloherty JP, Eichenwald CE, Stark AR, editors. Manual of Neonatal Care. 5th ed. Philadelphia: Lippincott Wiliams \& Wilkins, Pp. 579-88.

18. Kim SH, Park J (2001): Effect of phototherapy on bone metabolism in newborn rats. $\mathrm{J}$ Korean Soc Neonatal, 8(2):206-10.

19. Arora S, Narang GS, Singh G (2014): Serum calcium levels in preterm and term neonates on phototherapy. J Nepal Paediatr Soc., 34: 24-28. 